\title{
Time dependent dynamics of wound complications after preoperative radiotherapy in Extremity Soft Tissue Sarcomas
} \author{
Rick L. Haas ${ }^{\text {a, }}$, * \\ a Department of Radiation Oncology, Netherlands Cancer Institute, Amsterdam, the Netherlands \\ ${ }^{\mathrm{b}}$ Department of Surgical Oncology, Netherlands Cancer Institute, Amsterdam, the Netherlands \\ c Department of Pathology, Netherlands Cancer Institute, Amsterdam, the Netherlands \\ d Department of Radiation Oncology, LUMC, Leiden, the Netherlands \\ e Department of Orthopedic Surgery, LUMC, Leiden, the Netherlands
}

Jules Lansu a, Jan Groenewegen a , Frits van Coevorden ${ }^{\mathrm{b}}$, Winan van Houdt ${ }^{\mathrm{b}}$, Alexander C.J. van Akkooi ${ }^{b}$, Hester van Boven ${ }^{c}$, Michiel van de Sande ${ }^{\mathrm{e}}$, Marcel Verheij ${ }^{\mathrm{a}}$,

\section{A R T I C L E I N F O}

\section{Article history:}

Accepted 17 September 2018

Available online 6 October 2018

\section{Keywords:}

Extremity soft tissue sarcoma

ESTS

Soft tissue sarcoma

STS

Radiotherapy

Wound complication

Prognostic factor

Risk factor

\begin{abstract}
A B S T R A C T
Aims: The purpose of the study was to investigate the time dependent dynamics of wound complications and local control after preoperative radiotherapy (RT) in Extremity Soft Tissue Sarcomas (ESTS).

Patients \& methods: In this retrospective cohort study, all patients treated for an extremity sarcoma with pre-operative radiotherapy followed by surgery were identified from a prospectively maintained database. A wound complication (WC) was defined as any local complication of the surgical area requiring intervention, hospital readmission or significant extension of the initial admission period.

Results: A total of 191 preoperatively irradiated ESTS patients were included in this study. WC was seen in $31 \%$ of the patients $(n=60)$. WC started after a median time of 25 days from surgery, with a median duration of 76 days. Adiposity, smoking and a lower extremity or superficial tumor localization were significantly correlated with an increased WC rate. Risk factors for a duration of WC $\geq 120$ days are early development of WC ( $\leq 21$ days after surgery) and smoking. Local control rates after 1,3 and 5 years were $99 \%, 93 \%$ and $93 \%$, respectively.

Conclusion: Approximately one-third of patients selected for preoperative RT develops a WC, typically in smoking, adipose patients with superficial tumor localizations in the lower extremity. Based upon the well-established superior long-term functional outcome, maintained excellent local control rates and the temporary nature of the WC issue, preoperative RT remains our preferred treatment. Although, in patients at high risk of WC, post-operative RT might be considered.
\end{abstract}

๑) 2018 Elsevier Ltd, BASO The Association for Cancer Surgery, and the European Society of Surgical Oncology. All rights reserved.

\section{Introduction}

Soft tissue sarcomas (STS) are a rare and heterogeneous group of malignancies, accounting for less than $1 \%$ of all cancers. STS may originate from any connective tissue site in the body, and with

\footnotetext{
* Corresponding author. Department of Radiation Oncology, The Netherlands Cancer Institute, Plesmanlaan 121, 1066 CX, Amsterdam, the Netherlands.

E-mail addresses: j.lansu@nki.nl (J. Lansu), j.groenewegen@nki.nl (J. Groenewegen), f.v.coevorden@nki.nl (F. van Coevorden), w.v.houdt@nki.nl (W. van Houdt), a.v.akkooi@nki.nl (A.C.J. van Akkooi), h.v.boven@nki.nl (H. van Boven), michielvds@me.com (M. van de Sande), m.verheij@nki.nl (M. Verheij), r. haas@nki.nl (R.L. Haas).
}

roughly three fourth of the tumors located in the extremities this is the most common site of involvement [1]. Extremity soft tissue sarcomas (ESTS) are diagnosed frequently after a delay, due to the painless presentation and the rarity of the disease, resulting in large tumor masses, with a mean tumor diameter of $10 \mathrm{~cm}$ at time of diagnosis [2].

Limb sparing surgery combined with radiotherapy (RT) provides excellent 5-year local control rates of $88 \%$ or higher [3-6]. Preoperative RT is associated with a higher rates of wound complications (WC) compared to postoperative RT $[4,7,8]$. As a result, quality of life and the functionality of the limb may be somewhat worse in the first months after treatment, but with longer follow up, less radiation-induced fibrosis, joint stiffness and better long-term 
functional outcome is seen as compared to patients treated with postoperative RT [9-11].

Localization in the proximal lower extremity [4,11-15] and tumor diameter greater than $8-10 \mathrm{~cm}[4,8,11,15,16]$ have been identified as risk factors for developing WC in ESTS patients. In addition, diabetes, smoking and adiposity have turned out to be of prognostic value with respect to the occurrence of WC in two earlier retrospective series [11,16].

Incidence and prognostic factors for WC have been subject of investigations in earlier series [4,11-18], however, the timing of occurrence and factors affecting the duration of WC have, to the best of our knowledge, never been reported. In fact, it is not only the risk of development of a WC, but also its duration, which impacts on quality of life and health care costs. Obviously, both should be taken into account when choosing between preoperative and postoperative RT in ESTS in counselling individual patients.

The aim of this retrospective study was to evaluate the time dependent dynamics of WC and local tumor control after surgery and preoperative RT in ESTS in our tertiary referral sarcoma center by exploring our prospectively maintained database. To achieve this goal, we investigated proposed prognostic factors in relation to the occurrence and timing of WC during the treatment of ESTS.

\section{Patients and methods}

Patients

Between August 2003 and June 2017 a total of 541 patients were diagnosed with an ESTS in our sarcoma multidisciplinary team. RT was one of the treatment modalities in 342 patients, of whom 215 were irradiated preoperatively and 127 postoperatively. Twentyfour patients underwent subsequent surgery elsewhere and were excluded due to insufficient follow up data. Finally, data on 191 preoperatively irradiated ESTS patient were available for this analysis. An overview of the patient selection process is given in Fig. 1.

All pathological diagnoses were confirmed by a dedicated sarcoma pathologist. All histological subtypes of adult ESTS patients treated with preoperative RT were included. Patients with STS originating from other localizations than the extremities, previous RT to the site of involvement and palliative treatment intention or metastasized disease at time of diagnosis were not taken into consideration.

\section{Endpoints}

Primary endpoints were the occurrence and course of WC following surgical resection as well as local tumor control. WC was defined as any local complication of the surgical area requiring surgical intervention under general or regional anesthesia, hospital readmission or significant extension of the initial admission period. Surgical intervention under anesthesia consisted of wound repair (debridement, negative pressure therapy, drainage of seroma and/ or hematoma) or secondary wound closure (rotationplasty, free flap, skin graft). Intravenous antibiotic therapy and multiple times of outpatient seroma aspiration were also considered as WC. In contrast, oral antibiotics and a single seroma aspiration were not considered as WC. In addition, the time interval between surgery and occurrence of WC and between development and healing of WC were recorded. The date of reported wound closure was regarded as the date of healing of the WC. In case of multiple WC, the date of development of the first and date of disappearance of the last WC were used for the duration analysis. The Clavien-Dindo scale was used to classify WC [19]. Metastasis Free Survival (MFS), Progression Free Survival (PFS), Disease Specific Survival (DSS) and

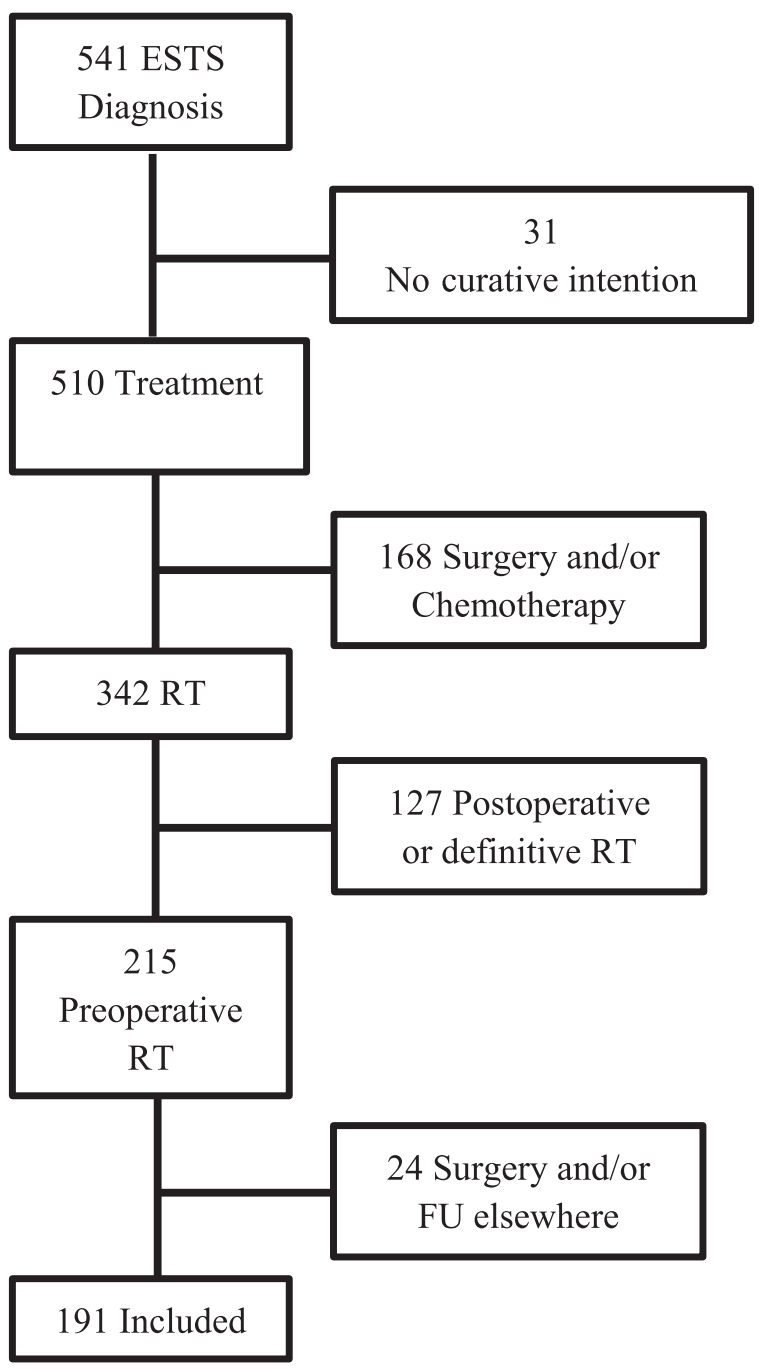

Fig. 1. Patient selection.

Overall Survival (OS) were defined as secondary endpoints in this study. All time-to-failure endpoints were calculated from date of diagnosis, except time to WC which was counted from date of surgery.

\section{Data collection and definitions}

After Ethics Committee approval, patient records were retrospectively reviewed to extract patient demographics, tumor characteristics, treatment details and clinical outcome. Proposed prognostic factors as adiposity, hypertension, diabetes and smoking were defined as $B M I \geq 30$, systolic pressure $\geq 140 \mathrm{mmHg}$, a medical history comprising diabetes and smoking during the period between start of RT and wound closure, respectively. Tumor diameter was assessed preoperatively on MRI and postoperatively in the resected tumor specimen by the pathologist. Tumor depth was evaluated as superficial or deep to the fascia on MRI, with a deep classification in case of fascia invasion.

\section{Treatment}

Gross Tumor Volume consisted of visualized tumor volume on gadolinium-enhanced, T1-weighted MRI and was expanded by 
$15 \mathrm{~mm}$ (40 mm in cranio-caudal direction) to the Clinical Target Volume (CTV), prior to adding $10 \mathrm{~mm}$ in all directions for conversion to the final Planned Target Volume [20]. An edit of the CTV was performed in case of overlap with natural barriers by anatomical structures such as fasciae, joint or bone. Limb sparing definitive tumor resection was performed by a dedicated oncologic surgeon, while wide resection margins were attempted in all cases. The main indication for involvement of a plastic surgeon for closure was a resection leading to a larger skin defect not suitable for primary closure. Other indications were resections where an area of bone, major vessels or other vital structures would be too exposed after primary closure, potentially leading to anticipated complications or symptoms, or resections in recurrences where previous and/or current radiotherapy and/or previous wound complications made these resections high-risk for new wound healing problems.

\section{Statistical analysis}

Chi-squared tests or independent-samples T-tests were used to assess differences between groups. Univariate analysis by (binary) logistic regression was performed to identify prognostic factors, and they were added to the multivariate analysis if $\mathrm{p} \leq 0.20$ was reached. All statistical tests were 2 -sided: $p \leq 0.05$ was considered as statistically significant. All analyses were conducted by using IBM statistics SPSS Statistics version 22 for Windows.

\section{Results}

\section{Baseline characteristics}

An overview of characteristics with respect to patient, tumor and treatment is presented in Table 1 . As a consequence of an anticipated higher risk of WC, plastic reconstruction was seen more frequently in the WC subgroup $(\mathrm{p}<0.001)$. Tumor size was, although not significantly, slightly smaller in the WC group compared to the group without WC. The largest median tumor diameter was seen in the proximal lower extremity $(12 \mathrm{~cm})$, followed by the proximal upper extremity $(9 \mathrm{~cm})$ and the distal lower extremity $(8 \mathrm{~cm})$, while the smallest median tumor diameter was observed in the distal upper extremity $(4 \mathrm{~cm})$. Tumors with a localization deep to the fascia $(12 \mathrm{~cm})$ were significantly $(\mathrm{p}<0.001)$ larger in comparison to superficial tumors $(6 \mathrm{~cm})$.

\section{Treatment}

In the majority of cases $50 \mathrm{~Gy}$ was given in once-daily fractions of $2 \mathrm{~Gy}(85 \%, \mathrm{n}=163)$, while $36 \mathrm{~Gy}$ in $2 \mathrm{~Gy}$ fractions $(5 \%, \mathrm{n}=10)$ and $45 \mathrm{~Gy}$ in $1.8 \mathrm{~Gy}$ fractions ( $4 \%, \mathrm{n}=7$ ) were the second and third most frequently used irradiation schedules. Other irradiation schedules performed were $39 \mathrm{~Gy}$ in $3 \mathrm{~Gy}$ fractions $(\mathrm{n}=5), 45 \mathrm{~Gy}$ in $2.5 \mathrm{~Gy}$ fractions $(n=2), 40 \mathrm{~Gy}$ in $2 \mathrm{~Gy}$ fractions $(\mathrm{n}=2), 46 \mathrm{~Gy}$ in $2 \mathrm{~Gy}$ fractions $(n=1)$ and $25 \mathrm{~Gy}$ in $5 \mathrm{~Gy}$ fractions $(\mathrm{n}=1)$. Reasons for not prescribing the standard $50 \mathrm{~Gy}$ in 25 fractions included frailty, old age, travel distance, proximity of a joint, progressive disease, study participation or a combination of those. In 21 out of 23 patients with recurrent disease or incomplete resection elsewhere $50 \mathrm{~Gy}$ in $2 \mathrm{~Gy}$ fractions was given, while two patients were irradiated to $45 \mathrm{~Gy}$, one in $1.8 \mathrm{~Gy}$ - and one in $2.5 \mathrm{~Gy}$ fractions, all with curative treatment intention. Delayed surgery due to acute radiotherapy toxicity was not observed in any of the patients. Neoadjuvant chemotherapy given in only 2 cases. Surgery was performed after a median of 6 weeks after the last RT fraction (range; 0 weeks due to progression on RT requiring early resection to 13 weeks due to a second primary malignancy requiring intervention before surgery of the sarcoma). Resection margins were negative (R0), microscopically positive (R1) and macroscopically positive (R2) in 113 (86\%), 16 (12\%) and 2 (2\%) patients, respectively.

\section{Wound complications}

In this cohort, WC were observed in 60 out of 191 patients (31\%). From these 60 patients, 12 had multiple WC, mostly consisting of both infection and necrosis. According to the Clavien-Dindo scale, 13 patients with grade II, 16 patients with grade IIIa, 31 patients with grade IIIb and no patients with grade IV or V wound complications were observed. The highest WC rate was seen among patients with tumors localized in the distal lower extremity (37\%), while the lowest rate was observed in the distal upper extremity (7\%). The WC rate by tumor localization is presented in Fig. 2. With a WC rate of $23 \%$, relatively few WCs were observed within the subgroup of patients irradiated with a radiation dose constrained $\leq 45$ Gy $(\mathrm{n}=31, \mathrm{p}=0.27)$.

An overview of proposed prognostic factors for development of WC is given in Table 2. Superficial tumor localization (OR 2.81, 95\% CI $1.45-5.44 ; \mathrm{p}=0.002$ ), adiposity (OR $3.59,95 \%$ CI $1.61-8.00$; $\mathrm{p}=0.002$ ) and smoking (OR 3.97, 95\% CI 1.70-9.20; $\mathrm{p}=0.001$ ) were significantly correlated with an increased WC rate in univariate analysis. Furthermore, these factors maintained statistical significance (respectively OR 4.06, 95\% CI 1.86-11.31; p < 0.001, OR 4.05, 95\% CI 1.67-9.84; $\mathrm{p}=0.002$ and 4.59, 95\% CI 1.86-11.30; $\mathrm{p}=0.001)$ in multivariate analysis. Although localization in the lower extremity was not significant in univariate analysis (OR 2.36, 95\% CI 0.85-6.56; $\mathrm{p}=0.098$ ), it reached a level of statistical significance in multivariate analysis (OR 4.98, 95\% CI 1.53-16.22; $\mathrm{p}=0.008)$. No other significant prognostic factors for development of a WC were identified.

Median time interval from surgery to the occurrence of a WC was 25 days (range $0-130$ ). Median duration of WC was 76 days (range 4-312 days). The distribution of the time interval to occurrence and duration of WC are shown in Fig. 3. Mean and median duration of WC by tumor localization is presented in Fig. 2. Longer persistence of WC in lower extremity was observed compared to the upper extremity (mean and median duration of respectively 91 and 77 days vs 36 and 12 days). WC duration $\geq 120$ days (75th percentile) was observed more frequently if the WC occurred within 21 days after surgery, compared to delayed ( $>21$ days) WC ( $38 \%$ vs $15 \%, \mathrm{p}=0.035$ ). Smoking turned out to be the only prognostic factor for development of a WC duration of $\geq 120$ days (OR 4.33, 95\% Cl 1.39-13.49, $\mathrm{p}=0.011$ ). Long-lasting WC ( $\geq 120$ days) mainly consisted of necrosis-related issues, often in combination with seroma and/or infection.

Plastic reconstruction was performed more frequently for nonprimary (vs primary) tumors $<10 \mathrm{~cm}$ (vs $>10 \mathrm{~cm}$ ) at distal (vs proximal) and superficial (vs deep) tumor localizations. No significant differences were noted with respect to smoking and adiposity between regular wound closure and plastic reconstruction. Patients with plastic reconstruction were significantly older (61 vs 56 years old, $\mathrm{p}=0.010$ ) and had significantly smaller tumors ( 7.6 vs $11.8 \mathrm{~cm}$ on preoperative MRI, $\mathrm{p}<0.001)$. No significant differences were found between these groups regarding the time dependent dynamics of WC.

\section{Local tumor control}

Out of 191 patients, 9 patients (5\%) experienced a local relapse after a median follow-up of 21 months (range 1-130 months). Local tumor control rates after 1, 3 and 5 years are 99\%, 93\% and 93\%, respectively. No significant differences in local tumor control were found between histological subtypes $(\mathrm{p}=0.189)$ and tumor 
Table 1

Patient, tumor and treatment characteristics. Significant differences are marked.

\begin{tabular}{|c|c|c|c|c|}
\hline Characteristic & Total & Wound complication (\%) & No wound complication (\%) & $P$ Value \\
\hline Number of patients & 191 & $60(31)$ & $131(69)$ & \\
\hline Gender & & & & 0.609 \\
\hline Male & 103 & $34(57)$ & $69(53)$ & \\
\hline Female & 88 & $26(43)$ & $62(47)$ & \\
\hline Age (years) & & & & 0.271 \\
\hline Mean [SD] & $57[15]$ & $56[14]$ & $58[15]$ & \\
\hline Median [range] & $60[19-92]$ & $57[24-84]$ & $61[19-92]$ & \\
\hline \multicolumn{5}{|l|}{ Comorbidity and smoking } \\
\hline Adiposity & 30 & $17(28)$ & $13(10)$ & 0.001 \\
\hline Hypertension & 69 & $23(38)$ & $46(35)$ & $\overline{0.672}$ \\
\hline Diabetes & 22 & $9(15)$ & $13(10)$ & 0.310 \\
\hline Smoking & 27 & $16(27)$ & $11(8)$ & $\underline{0.001}$ \\
\hline Presentation & & & & $\overline{0.104}$ \\
\hline First presentation & 168 & $49(81)$ & $119(91)$ & \\
\hline Recurrence & 8 & $4(7)$ & $4(3)$ & \\
\hline Incomplete resection elsewhere & 15 & $7(11)$ & $8(6)$ & \\
\hline \multicolumn{5}{|l|}{ Mean tumor size ${ }^{a}(\mathrm{~cm})$} \\
\hline Preoperative [SD] & $10.55[5.84]$ & $10.11[5.72]$ & $10.75[5.91]$ & 0.492 \\
\hline Postoperative [SD] & $9.93[6.07]$ & $9.12[5.70]$ & $10.33[6.23]$ & 0.216 \\
\hline Tumor depth & & & & $\underline{0.002}$ \\
\hline Superficial to fascia & 54 & $26(43)$ & $28(21)$ & \\
\hline Deep to fascia & 137 & $34(57)$ & $103(79)$ & \\
\hline Tumor grade & & & & 0.466 \\
\hline Low & 14 & $6(10)$ & $8(6)$ & \\
\hline Intermediate & 76 & $26(43)$ & $50(38)$ & \\
\hline High & 79 & $25(42)$ & $54(41)$ & \\
\hline Indeterminate & 22 & $3(5)$ & $19(15)$ & \\
\hline Histologic subtype & & & & 0.138 \\
\hline Liposarcoma & 56 & $21(35)$ & $35(27)$ & \\
\hline Leiomyosarcoma & 15 & $6(10)$ & $9(7)$ & \\
\hline Fibrosarcoma & 34 & $11(18)$ & $23(18)$ & \\
\hline UPS & 61 & $15(25)$ & $46(35)$ & \\
\hline Other & 25 & $7(12)$ & $18(14)$ & \\
\hline Tumor localization & & & & 0.145 \\
\hline Proximal lower extremity & 123 & $40(67)$ & $83(63)$ & \\
\hline Distal lower extremity & 40 & $15(25)$ & $25(19)$ & \\
\hline Proximal upper extremity & 14 & $4(7)$ & $10(8)$ & \\
\hline Distal upper extremity & 14 & $1(2)$ & $13(10)$ & \\
\hline Surgical margins & & & & 0.494 \\
\hline RO & 162 & $49(82)$ & $113(86)$ & \\
\hline $\mathrm{R} 1$ & 26 & $10(17)$ & $16(12)$ & \\
\hline $\mathrm{R} 2$ & 3 & $1(2)$ & $2(2)$ & \\
\hline Method of closure & & & & $\underline{0.001}$ \\
\hline Primary wound closure & 131 & $31(52)$ & $100(76)$ & \\
\hline Plastic reconstruction & 60 & $29(48)$ & $31(24)$ & \\
\hline Follow up (months) & & & & 0.967 \\
\hline Mean [SD] & $31[28]$ & $31[28]$ & $31[28]$ & \\
\hline Median [range] & $20[1-130]$ & $20[5-119]$ & $21[1-130]$ & \\
\hline
\end{tabular}

a Size was measured preoperatively on MRI and postoperatively on the pathologic specimen, UPS= Undifferentiated Pleomorphic Sarcoma.

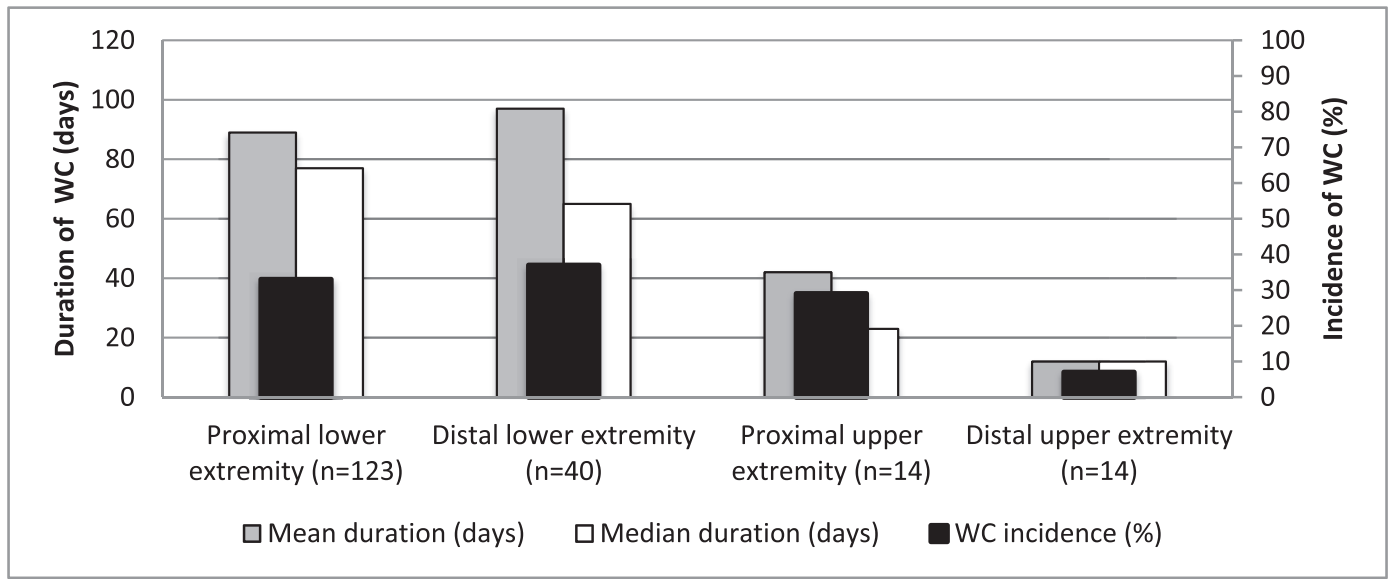

Fig. 2. Duration and incidence of WC by tumor localization. 
Table 2

Prognostic factors wound complication.

\begin{tabular}{|c|c|c|c|c|}
\hline Prognostic factor & OR Univariate [95\%CI] & $p$ & OR Multivariate [95\%CI] & $p$ \\
\hline $\mathrm{TD}>10 \mathrm{~cm}$ & $0.68[0.36-1.27]$ & 0.228 & & \\
\hline Superficial tumor & $2.81[1.45-5.44]$ & $\underline{0.002}$ & $4.06[1.86-11.31]$ & $\leq \underline{0.001}$ \\
\hline Age $^{\odot}$ & $0.99[0.97-1.01]$ & $\overline{0.227}$ & & \\
\hline Lower extremity & $2.36[0.85-6.56]$ & 0.098 & $4.98[1.53-16.22]$ & 0.008 \\
\hline Adiposity & $3.59[1.61-8.00]$ & 0.002 & $4.05[1.67-9.84]$ & $\overline{0.002}$ \\
\hline Hypertension & $1.15[0.61-2.16]$ & $\overline{0.667}$ & & \\
\hline Diabetes & $1.60[0.64-3.98]$ & 0.311 & & \\
\hline Smoking & $3.96[1.70-9.20]$ & $\underline{0.001}$ & $4.59[1.86-11.30]$ & $\underline{0.001}$ \\
\hline
\end{tabular}

$\mathrm{CI}=$ Confidence Interval, $\mathrm{OR}=$ odds ratio, $\mathrm{TD}=$ Tumor Diameter, ${ }^{\odot}=$ continuous variable.
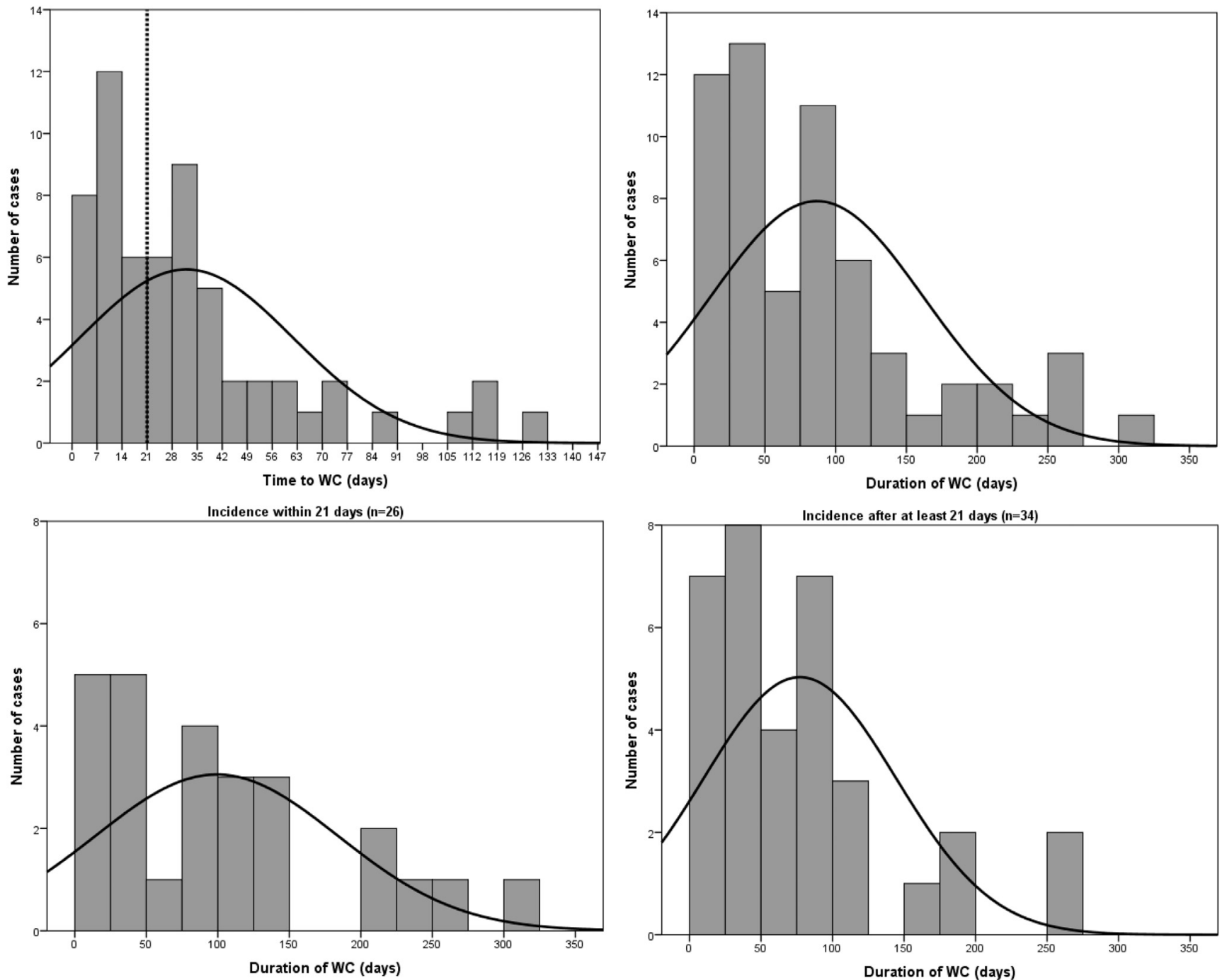

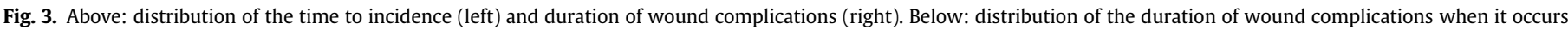

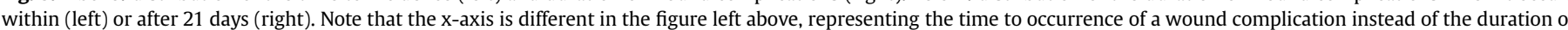
it.

localizations $(\mathrm{p}=0.462)$. Out of 31 patients who were irradiated with a dose $\leq 45 \mathrm{~Gy}$, one patient relapsed locally.

\section{Secondary endpoints}

MFS rates after 1, 3 and 5 years were respectively $85 \%, 59 \%$ and $56 \%$. PFS rates at the same time points were $84 \%, 57 \%$ and $54 \%$, while the rates for DSS were $97 \%, 84 \%$ and $76 \%$, respectively. OS was
$95 \%$ at 1 year, $80 \%$ at 3 years and $70 \%$ at 5 years. No significant differences were found between histologic subtypes and tumor localizations.

\section{Discussion}

Adipose patients with superficial tumors in the lower extremity who do not stop smoking are particularly prone for wound 
complications after preoperative RT. Both smoking during treatment period and early occurrence of a wound complication are associated with a long duration of wound complication. Although median WC duration showed to be longest (77 days) in the proximal lower extremity, distal lower extremity showed a median duration of only 12 days shorter, and even had a considerably higher mean WC duration due to 3 cases with a duration of $\geq 8$ months. Development of WC in the proximal lower extremity is possibly related to dysfunction of the lymphatic drainage after surgery preceded by RT in that area, resulting in more edema and higher risk of infection. In addition, tumors in this area are on average larger in size and lead to more "dead space" after resection, which is associated with increased risk of seroma and hematoma. With respect to distal lower extremity tumors, we observed a relatively long duration of WC. A possible explanation for this could be the vascularization of the distal lower limb and the close proximity to the tibia with limited volume of soft tissue. The complexity of successful wound closure in this area, is illustrated by the fact that a plastic reconstruction was necessary in almost two-thirds of the cases, compared to less than a third in the total study population.

Differences in duration of WC with respect to tumor localization were noted in favor of the upper extremity, with the distal upper extremity in particular, however, this finding was not confirmed by statistical testing due to insufficient sample size in the upper extremity group $(\mathrm{n}=5)$.

As hypothesized, we found an association between early development ( $\leq 21$ days) and long-lasting WC ( $\geq 120$ days). Furthermore, smoking during the treatment period was revealed as a risk factor for long lasting WC, supporting our hypothesis that smoking does not only increase the risk of WC, but also interferes with WC recovery.

The WC rate of 31\% we observed, is in line with the $35 \%$ reported by O'Sullivan et al. [4] However, in contrast to O'Sullivan et al., we did not consider a single seroma aspiration without regional or general anesthesia as a WC. Furthermore, our WC rate after preoperative RT is also in line with WC rates in other retrospective series, with a range from 15 to $44 \%$ [7,8,12,15-17,21-28].

Identifying patients at high risk for WC is valuable in the selection of individual patients who are perhaps more suitable for postoperative rather than preoperative RT. Smoking, adiposity and a lower extremity or superficial tumor localization were significant prognostic factors for development of WC after preoperative RT in multivariate analysis.

In addition, probably due to a selection bias, significantly more WC were seen among patients with a plastic reconstruction, suggesting that our surgical oncologists are already selecting patients at high risk for WC and as such consult plastic surgeons for their help in wound closure $[28,29]$. Furthermore, it cannot be ruled out that some of the vascularized flaps used for wound closure have been partly in the preoperative radiation field, possibly contributing to the WC rate in these patients.

This paper confirms that a lower extremity tumor localization, as reported in literature, is a risk factor for development of a WC $[4,11,13,15,17]$. The importance of the role of tumor localization is emphasized even more by the finding that tumor depth appeared to be an independent prognostic factor for WC, which is in line with skin surface proximity $<3 \mathrm{~mm}$ as a risk factor for WC, suggested by Baldini et al. [16] The inherently larger skin defect of superficial tumors as compared to deep tumors, apparently, lead to detrimental conditions in terms of WC. Unfortunately, we did not have data regarding the different types of WC, however, one can hypothesize that a larger skin defect leads to an increased risk of wound dehiscence and necrosis. Smoking, adiposity and the necessity of plastic reconstruction as significant prognostic factors for WC after preoperative RT in our cohort are in line with previous publications. In the series of Moore et al., which partly comprises postoperatively irradiated and non-extremity STS patients, both smoking and adiposity were found to be significant predictors for WC, but they did not reveal a significant correlation between plastic reconstruction and an increased risk of WC [11]. In Baldini's cohort smoking and plastic reconstruction were also associated with increased risk of WC after preoperative RT, however, the impact of adiposity was not analysed [16]. Smoking and adiposity did not turn out to be a significant predictor of WC in Tseng's series, nor was a significant correlation revealed between plastic reconstruction and WC [17]. It is unclear whether Tseng's definition of smoking comprises ever smokers or current smokers.

Several studies found a tumor size $\geq 10$ (or 8 ) $\mathrm{cm}$ to be a risk factor for WC $[4,8,11,15,16]$. In this cohort, this could not be confirmed. Patients with small tumors (median $6 \mathrm{~cm}$ ) in the distal lower leg tended to have, although not significantly, the highest risk of WC (37\%). The fact that this subgroup contains a high proportion of superficial tumors (19 out of 40 patients) is a plausible explanation for this elevated WC rate. An overview of the most relevant literature is presented in Table 3.

Most likely due to the relatively small number of patients who were irradiated with doses up to $45 \mathrm{~Gy}$, we did not find a statistically significant difference in WC rate between the two different dose levels. The modest WC incidence of $23 \%$ in the lower dose subgroup, may, however, be clinically relevant.

Practical recommendations to minimize the WC incidence include a limitation of the RT volume and dose as low as reasonably possible from an oncological perspective. Previous data suggests, that there are certain subtypes of STS, for example myxoid liposarcomas (MLS), which are more sensitive to radiation [30,31]. Those patients might benefit from a dose reduction, potentially leading to less WC and (long-term) toxicity. For MLS, this is currently being investigated in the DOREMY study. Secondly, collaboration between radiation oncologist and plastic surgeon is

Table 3

An overview of the literature.

\begin{tabular}{|c|c|c|c|c|c|c|c|c|}
\hline Reference & $\begin{array}{l}\text { No. of } \\
\text { Patients }\end{array}$ & $\begin{array}{l}\text { Incidence } \\
\text { of } \mathrm{WC}\end{array}$ & Lower extremity & $\begin{array}{l}\text { Superficial to } \\
\text { fascia }\end{array}$ & Tumor size & Smoking & Adiposity & Diabetes \\
\hline Korah et al. [15] & 96 & $34 \%$ & $\begin{array}{l}\text { lower } 41 \% \text { vs upper } \\
11 \% \text { extremity } \\
p=0.004\end{array}$ & NA & $\begin{array}{l}>8 \mathrm{~cm} \mathrm{OR} \mathrm{not} \\
\text { provided } \\
\mathrm{p}=0.05\end{array}$ & NA & NA & NA \\
\hline Baldini et al. [16] & 84 & $37 \%$ & NS & NA & $\begin{array}{l}>10 \mathrm{~cm} \text { OR } 3.3 \\
\mathrm{p}=0.03\end{array}$ & OR $10.6 \mathrm{p}=0.05$ & NA & $\begin{array}{l}\text { OR } 5.6 \\
p=0.03\end{array}$ \\
\hline Tseng et al. [17] & 173 & $32 \%$ & $36 \%$ vs $17 \% p=0.03$ & NA & NA & NS & NS & NS \\
\hline Lansu et al. & 191 & $31 \%$ & $\begin{array}{l}34 \% \text { vs } 18 \% \text { OR } 4.978^{*} \\
p=0.008\end{array}$ & $\begin{array}{l}\text { superficial } 48 \% \text { vs } \\
\text { deep } 25 \% \text { OR } 4.064 * \\
p=0.000\end{array}$ & NS & $\begin{array}{l}\text { yes } 59 \% \text { vs no } 27 \% \\
\text { OR } 4.404^{*} \\
p=0.001\end{array}$ & $\begin{array}{l}\text { yes } 57 \% \text { vs no } 27 \% \\
\text { OR } 4.412^{*} \mathrm{p}=0.001\end{array}$ & NS \\
\hline
\end{tabular}

$\mathrm{NA}=$ not analysed, NS = not significant, $\mathrm{OR}=$ odds ratio, ${ }^{*}=$ in multivariate analysis 
important to minimize the dose in the flap used for the plastic reconstruction. Prior to radiation treatment the strategy for secondary wound closure should be discussed in a MDT, to prevent avoidable irradiation of the flap, which is likely to affect the wound healing process. Finally, modern approaches like IG-IMRT and VMAT may also reduce wound complication rates [6].

Despite an increased risk of WC, preoperative RT minimizes long-term irreversible edema, fibrosis and joint stiffness [9-11], while excellent local control is maintained. Several series have reported 5-year local control rates varying between $88 \%$ and $95 \%$ [3-6,21,24,32,33]. Data from our cohort confirm the excellent local control rates after preoperative RT with $93 \%$ at 5 years.

To the best of our knowledge, this is the largest series evaluating WCs after preoperative RT in patients with ESTS reported to date. However, this retrospective analysis of a prospective maintained tertiary referral center database, bears all the caveats of retrospective studies in general.

In conclusion, two-thirds of all ESTS patients selected for preoperative RT will exhibit an uneventful wound healing. For the onethird of all patients that actually do develop WC, it turned out to be a clinically meaningful and sometimes difficult to manage, but temporary event. Besides smoking and adiposity, both a lower extremity and superficial tumor localization are predisposing factors for wound complication after surgery following preoperative RT. In comparison to WC observed in the upper extremity, WC in the lower extremity tend to have a longer duration. Long-lasting WC typically occur within a month after surgery in patients who continue to smoke. Based on superior long-term functional outcome and maintained excellent local control rates, preoperative RT followed by resection remains the standard treatment for ESTS patients in our center. To avoid serious WC, postoperative RT could be considered for adipose patients who refuse to stop smoking during treatment with a superficial tumor localization in the lower extremity.

\section{Conflicts of interest}

None declared

\section{Funding}

This research was partly sponsored by the HDKT foundation (stitchting Honderd Duizend Keer een Tientje).

\section{References}

[1] Fletcher CDM, Unni KK, Mertens F. Pathology and genetics of tumours of soft tissue and bone. In: World health organization classification of tumours, vol. 5. Lyon, France: IARC Press; 2002.

[2] Smith GM, Johnson GD, Grimer RJ, et al. Trends in presentation of bone and soft tissue sarcomas over 25 years: little evidence of earlier diagnosis. Ann R Coll Surg Engl 2011;93D7:542-7.

[3] Yang JC, Chang AE, Baker AR, et al. Randomized prospective study of the benefit of adjuvant radiation therapy in the treatment of soft tissue sarcomas of the extremity. J Clin Oncol 1998;16(1):197-203.

[4] O'Sullivan B, Davis AM, Turcotte R, et al. Preoperative versus postoperative radiotherapy in soft tissue sarcoma of the limbs: a randomised trial. Lancet 2002:359:2235-41.

[5] Beane JD, Yang JC, White D, et al. Efficacy of adjuvant radiation therapy in the treatment of soft tissue sarcoma of the extremity: 20-year follow-up of a randomized prospective trial. Ann Surg Oncol 2014;21:2484-9.

[6] O'Sullivan B, Griffin AM, Dickie CI, et al. Phase 2 study of preoperative imageguided intensity modulated radiation therapy to reduce wound and combined modality morbidities in lower extremity soft tissue sarcoma. Cancer 2013;119(10):1878-84.

[7] Cheng EY, Dusenbery KE, Winters MR, Thompson RC. Soft tissue sarcomas: preoperative versus postoperative radiotherapy. J Surg Oncol 1996;61(2): 90-9.

[8] Cannon CP, Ballo MT, Zagars GK, et al. Complications of combined modality treatment of primary lower extremity soft-tissue sarcomas. Cancer 2006;107(10):2455-61.

[9] Davis AM, O'Sullivan B, Turcotte R, et al. Late radiation morbidity following randomization to preoperative versus postoperative radiotherapy in extremity soft tissue sarcoma. Radiother Oncol 2005;75:48-53.

[10] Davis AM, O'Sullivan B, Bell RS, et al. Function and health status outcomes in a randomized trial comparing preoperative and postoperative radiotherapy in extremity soft tissue sarcoma. J Clin Oncol 2002;20:4472-7.

[11] Moore J, Isler M, Barry J, Mottard S. Major wound complication risk factors following soft tissue sarcoma resection. EJSO 2014:40:1671-6.

[12] Bujko K, Suit HD, Springfield DS, Convery K. Wound healing after preoperative radiation for sarcoma of soft tissues. Surg Gynecol Obstet 1993;176:124-34.

[13] Schwartz A, Rebecca A, Smith A, et al. Risk factors for significant wound complications following wide resection of extremity soft tissue sarcomas. Clin Orthop Relat Res 2013;471:3612-7.

[14] Prendergast B, Fiveash JB, Gibbs CP, et al. Radiotherapy for soft tissue sarcoma of the proximal lower extremity. Sarcoma 2010;2010. https://doi.org/ 10.1155/2010/829498. Article ID 829498.

[15] Korah MP, Deyrup AT, Monson DK, et al. Anatomic tumor location influences the success of contemporary limb-sparing surgery and radiation among adults with soft tissue sarcomas of the extremities. Int J Radiat Oncol Biol Phys 2012;82:933-9.

[16] Baldini E, Lapidus M, Wang Q, et al. Predictors for major wound complications following preoperative radiotherapy and surgery for soft-tissue sarcoma of the extremities and trunk: importance of tumor proximity to skin surface. Ann Surg Oncol 2013;20:1494-9.

[17] Tseng JF, Ballo MT, Langstein HN, et al. The effect of preoperative radiotherapy and reconstructive surgery on wound complications after resection of extremity soft-tissue sarcomas. Ann Surg Oncol 2006;13:1209-15.

[18] Stevenson M, Ubbels J, Slump J, et al. Identification of predictors for wound complications following preoperative or postoperative radiotherapy in extremity soft tissue sarcoma. Eur J Surg Oncol 2018. https://doi.org/10.1016/ j.ejso.2018.02.002.

[19] Dindo D, Demartines N, Clavien PA. Classification of surgical complications: a new proposal with evaluation in a cohort of 6336 patients and results of a survey. Ann Surg 2004;240(2):205-13.

[20] Haas RL, Delaney TF, O'Sullivan B, et al. Radiotherapy for management of extremity soft tissue sarcomas: why, when, and where? Int J Radiat Oncol Bio Phys 2012;84:572-80.

[21] Kim B, Chen Y, Kirsch D, et al. An effective preoperative three-dimensiona radiotherapy target volume for extremity soft tissue sarcoma and the effect of margin width on local control. Int J Radiat Oncol Biol Phys 2010;77(3): $843-50$.

[22] Pollack A, Zagars GK, Goswitz MS, et al. Preoperative vs. postoperative radiotherapy in the treatment of soft tissue sarcomas: a matter of presentation. Int J Radiat Oncol Biol Phys 1998;42(3):563-72.

[23] Kunisada T, Ngan SY, Powell G, et al. Wound complications following preoperative radiotherapy for soft tissue sarcoma. EJSO 2002;28(1):75-9.

[24] Kuklo TR, Temple HT, Owens BD, et al. Preoperative versus postoperative radiation therapy for soft-tissue sarcomas. Am J Orthoped 2005;34(2):75-80.

[25] Mack LA, Crowe PJ, Yang JL, et al. Preoperative chemoradiotherapy (modified Eilber protocol) provides maximum local control and minimal morbidity in patients with soft tissue sarcoma. Ann Surg Oncol 2005;12(8):646-53.

[26] Wang D, Zhang Q Kirsch DG, et al. RTOG phase II trial of preoperative image guided radiotherapy (IG-RT) for primary soft tissue sarcoma of the extremity: acute toxicity report. Int J Radiat Oncol Biol Phys 2011;81(2):S117.

[27] Griffin A, Dickie C, Catton C, et al. The influence of time interval between preoperative radiation and surgical resection on the development of wound healing complications in extremity soft tissue sarcoma. Ann Surg Oncol 2015;22:2824-30.

[28] Barwick WJ, Goldber JA, Scully SP, et al. Vascularized tissue transfer for closure of irradiate wounds after soft tissue sarcoma resection. Ann Surg 1992;216: $591-5$.

[29] Kane JM, Gibbs JF, McGrath BE, et al. Large, deep high-grade extremity sarcomas: when is myocutaneous flap reconstruction necessary? Surg Oncol 1999;8:205-10.

[30] Betgen A, Haas R, Sonke J. Volume changes in soft tissue sarcomas during preoperative radiotherapy of extremities evaluated using cone-beam CT. J. Radiat Oncol. 2013:2:55-62.

[31] de Vreeze R, de Jong D, Haas R, et al. Effectiveness of radiotherapy in myxoid sarcomas is associated with a dense vascular pattern. Int J Radiat Oncol Biol Phys 2008;72:1480-7.

[32] Alektiar K, Brennan M, Healey J, Singer S. Impact of intensity-modulated radiation therapy on local control in primary soft-tissue sarcoma of the extremity. J Clin Oncol 2008;26:3440-4.

[33] Virkus W, Mollabashy A, Reith J, et al. Preoperative radiotherapy in the treatment of soft tissue sarcomas. Clin Orthop Relat Res 2012;397:177-89. 